\title{
Orta hat kapanma defektlerinde fetuin-a, osteopontin, total antioksidan ve oksidan düzeyleri
}

\section{The levels of fetuin-a, osteopontin, total antioxidant and oxidant in patients with midline closure defects}

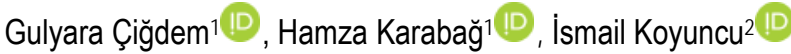 \\ ${ }^{1}$ Harran Üniversitesi Tıp fakültesi, Beyin ve Sinir Cerrahisi ABD, Şanlıurfa, Türkiye \\ 2 Harran Üniversitesi Tıp fakültesi, Tıbbi Biyokimya ABD, Şanlıurfa, Türkiye
}

öz.

Amaç: Orta Hat kapanma Defekti (OHD) yüksek morbidite ve mortalite ile ilişkili doğumsal spinal omurgaların birleşme kusurudur. OHD'li olan hastalarda Fetuin-A, Osteopontin, Total antioksidan ve oksidan seviyeleri bilinmemektedir. Bu çalışmada bu paramatrelerin OHD'li olan hastalarda düzeyleri ve hastalıkla olan ilişskisi araştııldı.

Materyal ve Metot: Çalışmaya, $0-5$ yaş grubu arasında OHD olan hastalar (Çalışma grubu, $n=80$ ) ve benzer yaşta sağıklı çocuklar (Kontrol grubu, $n=85$ ) olmak üzere 165 olgu alındı. OHD olan olgular Spina Bifida Occulta (Grup I, $n=22$ ), Spinal Meningosel veya Miyelomeningosel (Grup 2, n=26) ve Hidrosefalisi olan (Grup 3, n=31) olmak üzere 3 gruba ayrıldı. Dağılımların normal olup olmadığı tek yönlü Kolmogorov-Smirnov testi ile değerlendirildi. Gruplar arası karşılaştırmalarda, ki-kare, student $t$ testi, Mann-Whitney $\mathrm{U}$ testi ve Kruskal-Wallis varyans testleri kullanıld. Tüm olgularda Fetuin-A ve Osteopontin sandviç enzim bağlantill immün sistemi emici teknolojiye dayanarak ölçüldü, Total Antioksidan Status (TAS) ve Total Oksidan Status (TOS) spektrofotometrik olarak ölçüldü. TOS'un TAS'a oranılya oksidatif stres indeksi (OSi) hesaplandı.

Bulgular: Hasta ve kontrol grupları arasında TAS düzeyleri benzerdi $(\mathrm{p}=0.230)$. TOS ve OSi düzeyleri hastalarda, Fetuin-A ve Osteopontin değerleri ise kontrol grubunda daha yüksek bulundu (hepsi için, $p<0.05$ ). TAS düzeyleri hasta grupları arasında benzer, TOS, Fetuin-A, Osteopontin değerlerinde anlamlı farklıdı (hepsi için $p<0.05$ ). TOS, OSI ve Fetuin-A düzeyleri grup I den III'e doğru giderek azalırken, osteopontin düzeyleri grup l'de en yüksek, grup 2'de ise en düşük olarak bulundu.

Sonuç: OHD kapanma defekti, intrauterin dönemde meydana gelir. Embriyogenez aşamasında, ektodermal tabakadan gelişen nöral dokunun ve mezodermal tabakadan gelișen ve spinal kordun etrafinı saran kemik ve cildin orta hatta yetersiz kapanması ile sonuçlanan bir malformasyondur. Bu yetersiz kapanma nöral tüpün herhangi bir yerinde meydana gelebilir. Nöral tüpün histogenezi ve organogenezi tamamlanması için biyolojik ve kimyasal aktif maddelere intiyaç duyarlar. Bu nedenle OHD'li hastaların fizyopatolojisinde, TOS, OSI, Fetuin-A, Osteopontin değerlerinin rolü olabileceği düşünülmektedir.

Anahtar Kelimeler: Orta Hat Defekti, oksidatif stres, Osteopontin, Fetuin-A.

Abstract

Background: Midline closure defect malformation (NTD) is a congenital fusional defect of the posterior segments of spinal vertebrae which is associated with high morbidity and mortality. Fetuin-A, Osteopontin, total antioxidant and oxidant levels are unknown in patients with midline closure defects. In this study, the levels of these parameters in patients with NTD and their relationship with the disease were investigated.

Methods: The study included 165 patients (0-5 age group) with OHD (Study group, $n=80$ ) and healthy children of similar age (Control group, $n=85$ ). Patients with OHD were divided into three groups as Spina Bifida Occulta (Group I, $n=22$ ), Spinal Meningocele or Myelomeningocele (Group 2, $n=26$ ) and Hydrocephalus (Group 3, $n=31$ ). One-way Kolmogorov-Smirnov test was used to determine whether the distributions were normal or not. Ki-square, student $t$ test, Mann-Whitney $\mathrm{U}$ test and Kruskal-Wallis variance tests were used in the comparisons between the groups. Total antioxidant status (TAS) and total oxidant status (TOS) were measured spectrophotometrically. Oxidative stress index (OSI) was calculated with the ratio of TOS to TAS.

Results: TAS levels were similar between patient and control groups $(p=0.230)$. TOS and OSI levels were higher in patients, and fetuin-A and osteopontin values were higher in the control group (for all, $p<0.05$ ). TAS levels were similar between patient groups, however, TOS, fetuin-A, osteopontin values were significantly different ( $p<0.05$ for all). The levels of TOS, OSI and Fetuin-A were decreasing steadily from group I to III, whereas osteopontin levels were the highest in the group I and the lowest in the group 2.

Conclusion: $\mathrm{OHD}$ closure defect occurs during intrauterine period. In the embryogenesis stage, it is a malformation which results in inadequate closure of the midline spinal cord because of inadequate development of neural tissue from the ectodermal layer and because of inadequate development of the bone and skin from the mesodermal layer which surrounding the spinal cord. This insufficient closure can occur anywhere in the neural tube. They require biological and chemical active substances to complete the histogenesis and organogenesis of the neural tube. Therefore, it is thought that TOS, OSI, Fetuin-A and Osteopontin values may play a role during embryological development of OHD patients.

Keywords: Midline Closure Defect, oxidative stress, Osteopontin, Fetuin-A.

\section{Sorumlu Yazar I Corresponding Author}

Dr. Gulyara Çiğdem

Harran Üniversitesi Tıp Fakültesi, Beyin ve Sinir Cerrahisi ABD, Şanlıurfa, Türkiye.

Tel: +90 4143184748

e-mail: gulyara@hotmail.com

Geliş tarihi / Received: 28/05/2019

Kabul tarihi / Accepted: 05/08/2019

DOI: 10.35440/hutfd.571264 


\section{Giriş}

Orta Hat kapanma Defekti (OHD) santral sinir siteminin gelişimsel şekillenme bozuklukları ve arka bölümlerinin birleşme kusurudur (3). OHD anomaliler ile doğan bebekler ciddi sağlık sorununun yanında düşük yaşam kalitesi ile aile ve toplum için psikolojik bozukluklara, ekonomik kayıplara neden olmaktadır. Normal durumlarda oldukça az görülmesine rağmen ( $1 / 1000)$, ailede orta hat defektli bir bebek varsa, bu oran $60 / 1000$ 'e yükselmektedir. (4) Bölgemizde (Şanlıurfa ve yakınında bulunduğu iller) OHD görülme oranı Türkiye'deki diğer bölgelerde görülen $\mathrm{OHD}$ vakalarına göre daha fazla olacağı tahmin edilmektedir. Alt extremitelerde değişik oranlarda nörolojik defisitler, sfinkter disfonksiyonları, ortopedik bozukluklar gibi klinik tablolar ile karşımıza çıkmaktadır (5).

OHD çoğunlukla konjenital olup, etyopatogenezleri tam olarak bilinmemektedir. Günümüzde OHD hastalıklarına yönelik erken tanı ve tedavi teknikleri gelişmiş olması ve proflaksi yapılmasına rağmen böyle doğan hastalar erken yaşta ya kayıp edilmektedir veya defisitli bir yaşam sürmektedirler. Patogenezinde; vitamin ve mineral eksikleri (vitamin E, vitamin-B ve folik asit eksikliği), genetik, çevresel ve metabolik faktörler gibi çoklu nedenler yer almaktadır. OHD'inin meydana gelmesinde sitokinler Fetuin-A, Osteopontin (OPN) ve total antioksidant status (TAS), total oksidan status (TOS) nasıl bir rol aldığı bilinmemektedir. Bu çalışmada bu biyokimyasal belirteçlerin OHD'li olgularda düzeyleri ve başııca. OHD alt grupları olan Spina Bifida Occulta, Spinal Meningosel veya Miyelomeningosel ve Hidrosefalideki durumları araştıııld.

\section{Materyal ve Metot Hasta seçimi}

Çalışmaya Kasım 2015-Nisan 2018 tarihleri arasında Harran Üniversitesi Araştırma ve Uygulama Hastanesi Beyin ve Sinir Cerrahi, Yeni doğan ve Çocuk Hastalıkları polikliniğine ve kliniğine başvuran $0-5$ yaş arasında Orta Hat Kapanma Defekti olan (Çalışma grubu, $n=80$ ) ve olmayan (Kontrol grubu, $n=85$ vaka) toplam 165 vaka ardışık olarak alındı. Çalışma grubu Spina Bifida Occulta, Spinal Meningosel veya Miyelomeningosel ve Hidrosefalili olgular olmak üzere 3 ayrı gruba ayıldı. 5 yaş üstü, travma, spontan sistemik enfeksiyonlar (menenjit, bronşit, pnömoni, kızamık, kızamıkçık, kabakulak vb.), kalıtsal kas hastalıkları, metabolik hastalıkları (Fenilketonüri ve Histedinemi), organik asidemili hastalar ile enzim eksikliği olanlar ve medikal tedavi altında olan hastalar çalışma dışı bırakııdı. Bu hasta ve yakınlarına, detaylı bilgilendirme yazılı veya sözlü olarak yapılıp, hasta bilgilendirme formları imzalatıdı.

\section{Biyokimyasal ölçümler}

Tüm olgularda 3-5 ml önkol bölgesinden venöz kan örnekleri alındı. Hemogram, ALT, AST, BUN, Kreatinin vb), ölçümler hemen çalışıldı. Fetuin-A, OPN, TAS ve TOS çalışması için alınan kanlar 1500 devirde 10 dakika süreyle santrifuj edilerek serumları ayrıldı. Serumlar -80 C' derecede çalışıncaya kadar saklandı.

TOS seviyeleri piyasadaki mevcut tanı kitleri vasıtasıyla çalışıldı (Rel Assay, Gaziantep, Türkiye). Bu yöntem, serumda bulunan oksidanların asidik ortamda ferröz iyonu ferrik iyona dönüştürürmsine ve xylenol orange ile renkli bir kompleks oluştururması esasına dayanır. Serumda bulunan oksidanların miktarıyla ilişkili olan rengin şiddeti, spektrofotometrik olarak ölçüldü. Standard olarak H2O2 kullanıldı ve sonuçlar $\mu \mathrm{mol} \mathrm{H} 2 \mathrm{O} 2$ equivalent/L olarak hesaplandı.

Serum TAS seviyeleri piyasadaki mevcut tanı kitleri vasıtasıyla çalışıldı (Rel Assay, Gaziantep, Türkiye). Bu metoda göre; Fe2+-0-dianisidine kompleksi, hidrojen peroksid ile Fenton tipi reaksiyon oluşturarak $\mathrm{OH}$ radikalini oluşturur. Bu güçlü reaktif oksijen türü düşük pH'da renksiz o-dianisidine molekülü ile reaksiyona girerek sarı-kahverengi dianisidyl radikallerini oluştururlar. O-dianisidyl radikalleri ileri oksidasyon reaksiyonlarına katılarak renk oluşumunu artırmaktadır. Ancak örneklerdeki antioksidanlar bu oksidasyon reaksiyonlarını bastırarak renk oluşumunu durdurmaktadırlar. Örnekler spektrofotometrik olarak okutulduktan sonra sonuçlar mmol trolox eqv./L olarak hesaplandı.

Oksidatif Stres İndeksin (OSi) bir indikatörü olan OSl'nin hesaplanması için öncelikle TOS ve TAS'ın birimleri $\mu \mathrm{mol}$ şeklinde hesaplandı. Daha sonra, OSI (AU) $=((T O S$ $\mu \mathrm{mol} / \mathrm{L}) /(\mathrm{TAS} \mu \mathrm{mol} / \mathrm{L})) \times 100$ formülüne göre OSi hesaplandı. Kısaca bu TOS'un TAS'a bölünmesi ile elde edilmektedir

Serum OPN seviyeleri Insan OPN ELISA Kiti (Wuhan Fine Biotech. CO. Ltd.) vasıtasıyla çalışıldı. Serum Fetuin -A seviyeleri Insan FETUA (Fetuin A) ELISA Kiti (Wuhan Fine Biotech. CO. Ltd.) vasıtasıyla çalışıldı. Bu kitler, sandviç enzim bağlantılı immün sistemi emici teknolojiye dayanmaktadır. Anti-OPN ve Anti-FetuA antikorlar, 96 plaka üzerine önceden karıştııımıştır. Ayrıca, biyotin konjuge antiOPN-antikoru ve anti-FetuA-antikoru, tespit antikorları olarak kullanımıştır. Standartlar, test örnekleri ve biyotin konjuge saptama antikorları kuyulara sabitle eklenmiş ve yıkama tamponu ile yıkanmıştır. HPR-Streptavidin eklenmiş ve bağlanmamış konjugatlar yıkama tamponu ile yıkanmıştır. TMB substratları HRP enzimatik reaksiyonunu görselleştirmek için kullanıldı. TMB, asidik durdurma çözeltisi ilave edildikten sonra sarı renkte değiştirilen mavi renk ürünü üretmek için HRP ile katalize edildi. Sarı yoğunluğu, plakada yakalanan OPN ve FetuA miktarları ile orantılıdır. Bir mikroplak okuyucuda 450 nm'de absorbans ve daha sonra OPN ve FetuA konsantrasyonu hesaplanmıştır.

\section{İstatistiksel değerlendirme}

Sayısal veriler ortalama, standart sapma veya interquartil range, kategorik değişkenler ise sayı veya yüzde seklinde ifade edildi. Dağılımların normal olup olmadığı tek yönlü Kolmogorov-Smirnov testi ile değerlendirildi. Gruplar arası karşıllaştırmalarda, ki-kare, student t testi, Mann-Whitney U 
testi ve Kruskal-Wallis varyans testleri kullanıldı. İstatistikî anlamlılık için $p<0.05$ olması kabul edildi.

\section{Bulgular}

Çalışma ve kontrol grupları sayıları tablo 1 de yer almaktadır. Her iki grup arasında yaş ve cinsiyet dağılım benzerdi.

Tablo 1. Çalışmaya alınan olguların klinik ve laboratuvar değişkenlerinin karşılaştırılması

\begin{tabular}{llll}
\hline & $\begin{array}{l}\text { Çalışma } \\
\text { grubu }(\mathrm{n}=80)\end{array}$ & $\begin{array}{l}\text { Kontrol grubu } \\
(\mathrm{n}=85)\end{array}$ & P değeri * \\
\hline Yaş, yıl & $2 \pm 1,3$ & $1,7 \pm 1,2$ & 0,260 \\
Erkek, \% & 44 & 48 & 0,310 \\
$\begin{array}{l}\text { TAS, mmol } \\
\text { Trolox eqv./l }\end{array}$ & $1,18 \pm 0,14$ & $1,22+0,12$ & 0,230 \\
$\begin{array}{l}\text { TOS, mmol } \\
\text { H2O2 eqv.ll }\end{array}$ & $12,31 \pm 3,19$ & $10,13 \pm 1,97$ & $<0,001$ \\
OSi, AU & $1,06 \pm 0,34$ & $0,82 \pm 0,19$ & $<0,001$ \\
$\begin{array}{l}\text { Osteopontin, } \\
\text { ng/ml }\end{array}$ & $4,69 \pm 2,90$ & $6,74 \pm 3,45$ & $<0,001$ \\
$\begin{array}{l}\text { Fetuin A, } \\
\text { ng/ml }\end{array}$ & $1,03 \pm 0,48$ & $2,40 \pm 0,98$ & $<0,001$
\end{tabular}

Sayısal veriler ortalama + standart sapma, kategoriklar \% olarak yazıldı. ${ }^{*}$ nonparametrik Mann-Whitney $U$ testi ile hesaplandı.

AU; Arbitrary Unit, OSi; Oksidatif stres indeksi, TAS; Total antioksidan status, TOS; Total oksidan status.

$\mathrm{Bu}$, TAS değerinde kontrol ve vaka arasındaki gruplarda anlamlı bir fark olmadığını gösterdi. Ancak, TOS değerinde iki grup arasında anlamlı fark tespit edildi. P değerinin 0,05 den düşük olması, Oteopontin'de iki grup arasında anlamlı fark olduğunu gösterdi. Fetuin A da bu sonuçlara göre iki grup arasında anlamlı farklılık göstermekteydi. OSi, çaIışma grubunda, kontrollere göre daha yüksek bulundu ( $p<$ $0,001)$.

Çalışma grubu Spina Bifida Occultalı (Grup 1) 22, Spinal Meningosele veya Miyelomeningoselli (Grup 2) 26 ve Hidrosefalili 31 (Grup 3) olgu olmak üzere 3 ayrı gruba ayrıldı (Tablo 2).

Tablo 2. Çalışma grubundaki hastalar arsındaki laboratuvar parametreleri

\begin{tabular}{|c|c|c|c|c|}
\hline & Grup $1(n=22)$ & Grup $2(n=26)$ & Grup $3(n=31)$ & $P^{*}$ \\
\hline $\begin{array}{l}\text { TAS, } \\
\text { mmol } \\
\text { Trolox } \\
\text { eqv./l }\end{array}$ & $1,15 \pm 0,19$ & $1,20 \pm 0,13,3$ & $1,19 \pm 0,11$ & 0,47 \\
\hline $\begin{array}{l}\mathrm{TOS}, \\
\mathrm{mmol} \\
\mathrm{H} 2 \mathrm{O} 2 \\
\text { eqv.ll) }\end{array}$ & $13,73 \pm 2,75$ & $12,07 \pm 3,10$ & $11,54 \pm 3,31$ & 0,02 \\
\hline $\begin{array}{l}\text { OSI, } \\
\text { AU }\end{array}$ & $1,25 \pm 0,38$ & $1,02 \pm 0,30$ & $0,97 \pm 0,30$ & 0,01 \\
\hline $\begin{array}{l}\text { Osteo- } \\
\text { pontin, } \\
\text { ng/ml }\end{array}$ & $6,92 \pm 3,70$ & $3,22 \pm 1,68$ & $4,36 \pm 2,12$ & $<0,001$ \\
\hline $\begin{array}{l}\text { Fetuin } \\
\text { A, } \\
\mathrm{ng} / \mathrm{ml}\end{array}$ & $1,24 \pm 0,54$ & $1,04 \pm 0,61$ & $0,87 \pm 0,21$ & $<0,001$ \\
\hline
\end{tabular}

Veriler ortalama + standart sapma olarak yazıldı, * Kruskal-Wallis varyans analizi ile elde edildi. AU; Arbitrary Unit, OSI; Oksidatif stres indeksi, TAS; Total antioksidan status, TOS; Total oksidan status.
Her üç gruptaki hastaların TAS değeri benzerdi. Buna göre, TOS'ta 1. grupla 3. grup arasında anlamlı fark bulunmaktadır. Osteopontin değerleri; tüm gruplar arasında fark olduğunu göstermektedir. Fetuin A değerlerinde 1. grupla 3. grup arasında fark vardır. OSi değerleri; 1.grupla 2. grup ve 1. grupla 3. grup arasındaki anlamlı farkı göstermektedir.

\section{Tartışma}

Bu çalışma sonucunda, ODH olan çocuklarda sağlıklı kontrollere göre oksidatif stresin arttı̆̆ı, OPN ve Fetuin-A seviyelerinin azaldığı görüldü. Hastalığın beraberinde getirdiği kusurluluk ne kadar büyük ise o kadar TAS değerlerinin düştüğü; TOS ve oksidatif stress indeksinin ise arttığı görülmektedir.

Çocuklarda total oksidan ve antioksidan parametreler, spontan intraserebral kanamalı (ISK) preeklamptik anne bebeklerinde, anne sütü ile beslenenlerde ve sepsis gibi pek çok klinik durumlarda önemli rol oynadığı gösterilmiş̧ir (6-10). Antioksidatif/Oksidatif stres faktörleri, kemik gelişimine katkıda bulunan glikoprotein, Osteopentin ve FetuinA parametrelerinin $\mathrm{OHD}$ üzerindeki olumlu veya olumsuz etkileri araştırımıştır. (11)

OHD ile doğan çocuklar ile sağlıklı bireyler (kontrol grubu) arasında bakılan TAS değerleri çalışmamızda benzerlik göstermiştir. TAS değerleri, OHD derecesi daha hafif olan spina bifida occulta gibi (nörolojik defisitsiz hastalar) antioksidatif parametreler küçük bir farkla da olsa, ağır üriner ve anal sfinkterlerde eşlik eden disfonksyonları, nörolojik defisitli olan OHD olan hastalardan hafif yüksek bulundu. Bu da konjenital hastalıklarda, özellikle açık disrafizm ile seyreden patolojilerde oluşan oksidatif strese karşı antioksidan savunma mekanizmasının önemli rolü olabileceği kanaatini doğurmaktadır.

OHD ile doğan çocuklarda, TOS ve OSi değerleri daha yüksek sinir sistemindeki hasarı onaran antioksidan ile hasarı oluşturan ve şiddetini artıran (sitokinler, serbest radikaller, proteolitik enzimler...) oksidan maddeler arasında bir dengesizlik söz konusu olduğunu göstermektedir. OHD alt grupları arasında en düşük TOS ve OSi seviyeleri, ek nörolojik defisiti olmayan sadece konjenital hidrosefalisi olan hastalarda bulunmuştur. Ciddi organ ve hücre hasarı olan hastalarda (Spina Bifida Occulta, Spinal Meningosel ve Meningomiyelosel) TOS ve OSi bir miktar daha yüksek bulunmuştur. Bu sonuç, antioksidan savunma mekanizmaların bu tür hastalarda (OHD'li hastalarda) yetersiz olabileceğini düşündürmektedir. Buna karşı önlemlerin alınması için ileri araştırmaların yapııması gerekir.

OHD ile doğan bebeklerde, vertebral kanalın kemik yapısının kapanmasında çeşitli defektlerin yanı sıra, beyin ve spinal kordda çeşitli derecede anomaliler mevcuttur. OPN, Merkez Sinir Sisteminde (MSS) ekstrasellülar matrikste, osteoblastlarda ve fibroblastlarda bulunur; kemiğin büyümesi, gelişmesi ve mineralizasyonu ve MSS hasarlanmış 
nöral dokunun onarımında önemli rol oynar $(11,12)$. Açık spinal disrafizmi (Meningosel, Meningomiyelosel vs.) olan hastalarda, normal anatomik doku olmadığı için beyinkan bariyerinin bozuk olması da söz konusudur. Glukoz ve oksijen eksikliğinde, OPN'nin kan-beyin bariyeri ve beyin hücreleri üzerinde olumlu etkileri olduğu bilinmektedir $(13,14)$. Çalışmamızda OHD'li hastalarda TOS ve OSi düzeyleri daha yüksekti. Bu durum dokularda ve vücut sıvılarında anlamlı şekilde OPN ekspresiyonunu artırmaktadır (15). OPN, makrofaj ve lenfositlerde bulunan reseptörler ile etkinleşerek inflamatuar ve immun reaksiyonlarda rol alır. OHD hastalığı da inflamasyonun arttığı bir durum olup bu da OPN seviyesini artırmaktadır (16). OPN, Nitrik Oksit (NO), TNF-a ve IL-6'nın salınımını azaltır. Bu şekilde inflamasyonu azalttı̆ı̆ düşünülmektedir (17).

OPN'nin nörodejeneratif hastalıklarda protektif rolü olduğu, Alzheimer hastalığında (AD) arttığı, endojen hipoksi göstergesi olduğu ve nöronal remiyelinizasyona neden olduğu bilinmektedir $(18,19)$. OHD ile doğan çocuklarda OPN değerlerin daha düşük tespit edilmesi, spinal kanalı oluşturan kemik dokuda normal gelişimi, büyümeyi ve mineralizasyonu sağlayan hücrelerde (oteoblast, osteoklast, fibroblast vs.) OPN sentezi ve sekresyonunun azaldığını göstermektedir. Bu durum, OPN'nin omurga gelişimi için önemli rolünü gösterebilir.

Bu çalışmada, OHD olan hasta grupları arasındaki OPN değerleri anlamlı bir farklıık göstermekteydi. Nörolojik defisiti olmayan, beyin parankimi normal gelişmiş spina bifida occultalı hastalarda OPN değeri en yüksekti. Orta derecede nörolojik defisiti olan, geniş ve gergin fontaneller, yaygın ventrikulomegali ve beyin parankimi aplazisi veya hipopazisi olan konjenital hidrosefalili çocuklarda OPN değeri orta seviyede bulundu. Ciddi nörolojik kayıpları olan (alt extrimiteler paraplejik), omurga kanalından açık vertebral defektlerinde dışarı doğru fıtıklaşmış spinal kord ve meninklslerinde ciddi hasarı olan hastalarda ise OPN değeri en düşük bulundu.

Osteopontin multifonksiyonel non-kollajen fosfoglikoproteindir. (20) İki çeşit OPN vardır: birincisi sekretuar OPN (sOPN) ikincisi intraselular OPN (iOPN)'dir. (21) Spinal kanalı oluşturan kemik dokudaki OPN osteoblastların ve osteoklastların üzerinde induktif etkisi ile bu hücrelerin proliferasyonunu artırarak, spinal ve kraniyal disrafizmlerin oranları ve dereceleri düşebilir. Bu, nöroprotektör olarak normal sinir sistemi gelişimi için önemli bir parametredir. Bunun yanında başarılı implantasyona yol açan maternal ve embriyonik epitel arasındaki etkileşimden sorumlu faktörlerin arasında endometrial adgezyonunda ekstraselular matriks ligand olarak OPN düşünülmektedir. (22) Bu nedenle OPN'nin yüksek oranda bulunduğu besinlerin (süt, kemik suyu) gebelik sırasında bolca alınması önerilebilir.

Bir çalışmada akut koroner sendromlu + kalp kapak kalsifikasyonu olan 95 hasta ve akut koroner arter hastalı̆ı olan, ancak kalp kapak kalsifikasyonu olmayan 81 hasta incelenmiştir. Bu çalışmada, Fetuin-A negatif akut faz reaktanı olduğu tespit edilmiştir (23).

Fetuin-A'nın üriner sistemdeki taş oluşumu etiyopatogenezinde rolünün olmadığı, ancak OPN ile zayıf derecede pozitif yönde ilişki tespit edilmiştir (24), Alzeheimer hastalığının gelişiminde ve ilerlemesinde risk faktörü olduğu gösterilmiştir (25). Yunanistan'da yapıımış bir çalışmada ise kromozomun 21. çiftinde trisomisi tespit edilen fetüslü gebelerden ve euploid kromozomu tespit edilen fetüslü gebelerde; ikinci trimestirde amniyosentez ile amniyon sIVISI alınmıştır. Alınan amniyon sıvılarındaki Fetuin A incelemelerinde kromozomun 21. çiftinde trisomisi tespit edilen fetüslerde Fetuin A'nın daha düşük olduğu görülmüştür. Düşük seviye Fetuin A'nın büyüme kısıtlaması veya bozulmuş osteogenezis gibi sendromun özellikleri ile ilişkili olabilecek değişmiş metabolik yolaklarla bir ilişkiye işaret edebilir (26).

Genetik olarak programlanmış normal kemik oluşumu osteogenezis olarak bilinir. Fetuin-A, kemikte yüksek oranda bulunur ve tüm kollajen olmayan kemik proteinlerinin $\%$ 25 'ini oluşturur. Fetuin-A proteini, kalsiyum ve fosfat grupIarını birbirine bağlayarak daha büyük agregatları oluşturur. Oluşturulmuş büyük agregatlar, albümin ve asidik plazma proteinleri ile bağlanarak kolloid hale gelip mineral iyonları stabilize eder. Fetuin-A eksikliği yumuşak doku kalsifikasyonuna neden olur (27). Fetuin-A kemik fenotipinde defekti olmayan farelerde, yaşla birlikte kemik oluşumunun arttığı, osteogenez ve kemik büyümesi için Fetuin A'nın gerekli olduğu gösterilmiş̧tir (28).

Çalışmamızda, OHD olan hastalarda Fetuin-A düzeyleri bir miktar daha düşük tespit edildi. Yeni doğan bebeklerde, Fetuin-A major plazma proteini olduğu halde, OHD olan hastalarda Fetuin-A'nın sentezi ve sekresyonunda azalma olduğu düşünülmektedir. Fetuin-A'nın düşük seviyelerde olması, kemik ve sinir sistemi dokularının gelişimini olumsuz yönde etkiler. Özelikle Fetuin-A seviyesinin düşük olması beyin dokusundaki kan-beyin bariyerinin tam olarak gelişimini olumsuz yönde etkiler. Çünkü, Fetuin A eksikliği endotel hücreleri tarafından oluşturulan sıkı bağlantıların gevşek olmasına neden olmaktadır (29). Gebelik sürecinde Fetuin A değerinin düşük olmasında spontan abortus ve erken doğum risklerinin yüksek olduğu görülmüştür (30; 26).

Çalışmamızın devamında OHD olan hasta grupları arasındaki Fetuin -A, Spina Bifida Occulta hastalarda en yüksek, Spinal Meningosel ve Meningomiyelosel hastalarında orta derecede yüksek, konjenital hidrosefali olanlarda ise en düşük seviyede bulundu. Bu sonuç, Fetuin A'nın beyin dokusunun gelişimi, kan-beyin bariyerinin korunması ve beyindeki endovasküler yapıların gelişiminde rolü olduğunu desteklemektedir.

Çalışmanın sınırlamaları; Hasta sayısının azlığı, inflamasyon markırlarının bakılmaması, BOS'da çalışılmamış olması ve hastalığı öngörmedeki yerinin hesaplanmamış 
olması en önemli sınırlamalarını oluşturmaktadır.

Sonuç; Orta Hat kapanma Defekti ile doğan bebeklerde, antioksidan mekanizmanın yetersiz olduğu görülmüştür. TOS ve oksidatif stresin arttığı durumlarda, antioksidan savunma mekanizmalarının yetersiz kalması sonucu organ hasarı oluşumu görülmüştür. Bu durum, hücre membranlarına, proteinlere ve en önemlisi DNA yapısına hasar vererek hücresel yıkıma (kemik ve sinir dokusunda) neden olur. Oksidatif stres değerleri ne kadar artarsa, doku ve organ hasarına bağlı OHD ile doğan bebeklerdeki malformasyon şiddeti o kadar artar. Artmış oksidatif strese bağı olarak gelişen Orta Hat kapanma Defektli bebeklerdeki OPN değerleri, kontrol grubuna göre daha düşük olarak tespit edilmiştir. Düşük OPN değerleri olan hastalarda kemik matriksinde oluşan doku hasarına bağlı olarak osteoblast aktivitesi de azalmış olur. Orta Hat kapanma Defekt ile doğan hastalarda, Fetuin-A değerleri ne kadar azalmış ise sinir dokusundaki hasarın derecesi de o kadar yüksek olarak tespit edilir.

TOS ve oksidatif stresin artması, OPN ve Fetuin-A düzeylerindeki azalmanın OHD'nin meydana gelmesinde rolünün olabileceğini düşündürmektedir.

\section{Kaynaklar}

1. Kaplan SÇ, Göçmez C, Dağgülli M. Myelodisplazik hastalarda nöroürolojik komplikasyonlar. Dicle Tıp Dergisi. 2014; 41(1): 234-237.

2. Üngüren $E$. Beynin Nöroanatomik ve nörokimsayal yapısının kişilik ve davranış üzerindeki etkisi. Alanya Uluslararası Alanya İşletme Fakültesi Dergisi, 2015; 7(1): 193-219.

3. Ünlü A, Bağdatoğlu C, Silav G, Aydın V, Güney Ö, Selçuki M. Orta hat kapanma kusurlarında kalsiyumun önemi. Türk nöroşirürji dergisi. 2001; 11: 111-116.

4. Ergül T. Türkiye'deki yüksek nöral tüp defekti sıklığı ve önlemek için yapabilecekler. Çocuk sağlığı ve hastalıkları dergisi. 2004; 47: 79-84.

5. Northrup H, Volcik KA. Spina bifida and other neural tube defects. Curr Probl Pediatr. 2000; 30(10): 313-332.

6. Çevik MU, Acar A, Yücel Y, Varol S, Akıl E, Arıkanoğlu A, Yüksel H. İntraserebral kanamalı hastaların kanında total oksidan/antioksidan durumunun araştırıması. Turk J Neurol. 2013; 19(1): 1-2.

7. Altunhan, H. Preeklamptik anne bebeklerinde total oksidan seviye, total antioksidan seviye ve paraoksonaz düzeyleri. Selçuk Üniversitesi Meram Tıp Fakültesi Çocuk Sağlığı Ve Hastalıkları Anabilim Dalı Neonatoloji Bilim Dalı, 2011; 40-43.

8. Alpınar A, Torun E, Özkaya E, Uzuner S, Erenberk U. Anne sütü ve mama ile beslenen süt çocuklarında toplam antioksidan düzeylerinin karşılaştırıması. Türk Ped Arş. 2012; 47: 95-98.

9. Şahin ÖK, Aksoy MÇ, Uz A, Dağdeviren BH. Deneysel sigara modelinde resveratrolün total oksidan/antioksidan kapasite üzerine etkilerinin araştırılması. SDÜ Sağlık Bilimleri Dergisi. 2015; 6(1): 10-14.

10. Annagür, A. Yenidoğan sepsisinde total antioksidan seviye, total oksidan seviye ve serum paraoksonaz düzeyleri. Selçuk Üniversitesi Meram Tıp Fakültesi Çocuk Sağlığı Ve Hastalıkları Anabilim Dalı Neonatoloji Bilim Dalı, 2011; 22-33, 42-44

11. Denhardt DT, Noda M. Osteopontin expression and function: Role in bone remodeling. J Cell Biochem. 1998; 72(30-31): 92-102.

12. Yu H, Liu X, Zhong Y. The effect of osteopontin on Microglia. Biomed Research International. 2017; 1-6.

13. Yılmaz, N. Kan-Beyin bariyerinin fizyopatolojisi. Van Tıp Dergisi. 2006; 13(1): 25-27.

14. Meller R, Stevens SL, Minami M, Cameron JA, King S, Rosenzweig H, Doyle K, Lessov NS, Simon RP, Stenzel-Poore MP. Neuroprotection by osteopontin in stroke. J Cereb Blood Flow Metab. 2005; 25(2): 217-225.

15. Fu Y, Hashimoto M, Ino H, Murakami M, Yamazaki M, Moriya H. Spinal root avulsion-induced upregulation of osteopontin expression in the adult rat spinal cord. Acta Neuropathol. 2004; 107(1): 8-16.

16. Denhardt DT, Guo X. Osteopontin: A protein with diverse functions. Faseb
J. 1993; 7(15): 1475-1482.

17. Rabenstein M, Vay SU, Flitsch LJ, Fink GR, Schroeter M, Rueger MA. Osteopontin directly modulates cytokine expression of primary microglia and increases their survival. J Neuroimmunol. 2016; 299:130-138.

18. Wung JK, Perry G, Kowalski A, Harris PL, Bishop GM, Trivedi MA, Johnson SC, Smith MA, Denhardt DT, Atwood CS. Increased expression of the remodeling-and tumorigenic-associated factor osteopontin in pyramidal neurons of the Alzheimer's disease Brain. Curr Alzheimer Res. 2007; 4(1): 6772.

19. Hasan I, Sekarutami SM, Aman RA, Siregar NC, Mulyadi R. The correlation between osteopontin level and radiation response of malignant gliomas at Cipto mangunkusumo hospital. Advances in Modern Oncology Reaserch. 2016; 2(6): 24-25.

20. Sudhir P. S, Jayashree V.Ganu,N. N. Osteopontin: A Novel Protein Molecule. Indian Medical Gazette, February 2012; 62-3.

21. Cantor $\mathrm{H}$, Shinohara Ml. Regulation Of T-Helper-Cell Lineage Development By Osteopontin: The İnside Story. Usa. Nat Rev Immunol, Feb, 2009; $9(2): 137-41$

22. Lessey B.A. Endometrial integrins and the establishment of uterine receptivity Human Reprodüction, 1998,13(3), 247-258.

23. Afşar, CU. Akut koroner sendromlu hastalarda serum fetuin-A düzeyi, kalp kapak kalsifikasyonu ve bunun diğer biyokimyasal parametrelerle ilişkisinin değerlendirilmesi. İstanbul: Sağlık Bakanlığı İstanbul Eğitim Ve Araştırma Hastanesi, 2009; 7 .

24. Yaman $F$, Aybek $H$, Aybek $Z$. Üriner sistem taş hastalığı etiyopatogenezinde fetuin-A ve Osteopontin. Türk Klinik Biyokimya Derg, 2014; 12(1): 21-29.

25. Smith ER, Nilforooshan R, Weaving $G$, Tabet N. Plasma fetuin-A is associated with the severity of cognitive impairment in mild-to-moderate Alzheimer's disease. J Alzheimers Dis., 2011; 24(2): 327-33.

26. Iliodromiti S, Vrachnis N, Samoli E, Iliodromiti Z, Pangalos C, Drakoulis N, et all. Fetuin A concentration in the second trimester amniotic fluid of fetuses with trisomy 21 appears to be Lower: Phenotypic considerations. Mediators of Inflammation, 2012; 1-4.

27. Jahnen-Dechent $W$, Heiss $A$, Schafer $C$, Ketteler M. Fetuin-A regulation of calcified matrix metabolism. Circulation Research, June 10, 2011; 108(12): 1494-509.

28. Brylka LJ, Köppert, S, Babler A, Kratz B, Denecke B, Yorgan TAet all. Postweaning epiphysiolysis causes distal femur dysplasia and foreshortened hindlimbs in fetuin-A-deficient mice. Plos One 2017 Oct 31;12(10), http://journals.plos.org/plosone/article?id=10.1371/journal.pone.0187030, Erişim tarihi: 5.5.2018.

29. Ryabukhin IA, Artemkina IV, Gurina OI, Sergienko VI, Chekhonin VP. Immunochemical assay of glia-specific antigens as a Criterion for blood-Brain barrier permeability in rats during acute intoxication with sodium barbital. Bull Exp Biol Med. 2001; 131(5): 502-504.

30. Kavak SB, Kavak EC, Sen A, Ilhan R, Kaya M, Sapmaz E, et all. Fetuin A concentration in the amniotic fluid of fetuses with down syndrome. J Genet Disor Genet Rep, 2015; 4(1). 